\title{
Marketing Models and the Lucas Critique
}

Harald J. van Heerde, Marnik G. Dekimpe and William P. Putsis, Jr.

\begin{tabular}{|l|l|}
\hline \multicolumn{2}{|l|}{ ERIM REPORT SERIES RESEARCH IN MANAGEMENT } \\
\hline ERIM Report Series reference number & ERS-2004-080-MKT \\
\hline Publication & August 2004 \\
\hline Number of pages & 21 \\
\hline Email address corresponding author & mdekimpe@rsm.eur.nl \\
\hline Address & Erasmus Research Institute of Management (ERIM) \\
& Rotterdam School of Management / Rotterdam School of \\
& Economics \\
& Erasmus Universiteit Rotterdam \\
& P.O. Box 1738 \\
& 3000 DR Rotterdam, The Netherlands \\
& Phone: +31 10408 1182 \\
& Fax: +31 104089640 \\
& Email: info@erim.eur.nl \\
& Internet: www.erim.eur.nl \\
\hline
\end{tabular}

Bibliographic data and classifications of all the ERIM reports are also available on the ERIM website: www.erim.eur.nl 


\section{ERASMUS RESEARCH INSTITUTE OF MANAGEMENT}

REPORT SERIES

\section{RESEARCH IN MANAGEMENT}

\begin{tabular}{|c|c|c|c|}
\hline \multicolumn{4}{|c|}{ BIBLIOGRAPHIC DATA AND CLASSIFICATIONS } \\
\hline Abstract & \multicolumn{3}{|c|}{$\begin{array}{l}\text { The Lucas critique has been largely ignored in the marketing literature. We present a number of } \\
\text { conditions under which the critique is most likely to (also) apply in marketing settings. Next, we } \\
\text { provide some perspectives on how to diagnose and accommodate the Lucas critique, and } \\
\text { identify various avenues for future research. }\end{array}$} \\
\hline \multirow{3}{*}{$\begin{array}{l}\text { Library of Congress } \\
\text { Classification } \\
\text { (LCC) } \\
\text { LCC Webpage }\end{array}$} & \multicolumn{3}{|l|}{ Mission: HF 5001-6182 } \\
\hline & \multicolumn{3}{|c|}{ Programme: HF 5410-5417.5 } \\
\hline & \multicolumn{2}{|c|}{ Paper: HF 5415.2+ } & Marketing research \\
\hline \multirow{5}{*}{$\begin{array}{l}\text { Journal of Economic } \\
\text { Literature } \\
\text { (JEL) } \\
\text { JEL Webpage }\end{array}$} & \multicolumn{3}{|l|}{ Mission: M } \\
\hline & \multicolumn{3}{|c|}{ Programme : C 44, M 31} \\
\hline & \multirow[t]{3}{*}{ Paper } & C 50 & Econometric Modelling \\
\hline & & D 84 & Expectations \\
\hline & & M 31 & Marketing \\
\hline \multicolumn{4}{|c|}{ Gemeenschappelijke Onderwerpsontsluiting (GOO) } \\
\hline \multirow[t]{3}{*}{ Classification GOO } & \multicolumn{3}{|l|}{ Mission: 85.00} \\
\hline & \multicolumn{3}{|c|}{ Programme: $85.03,85.40$} \\
\hline & \multicolumn{2}{|c|}{ Paper: $83.03,85.40$} & Methoden en technieken, Marketing \\
\hline \multirow[t]{3}{*}{ Keywords GOO } & \multicolumn{3}{|c|}{ Mission: Bedrijfskunde / Bedrijfseconomie } \\
\hline & \multicolumn{3}{|c|}{ Programme: Marketing, Methoden en technieken, operations research } \\
\hline & \multicolumn{3}{|c|}{ Paper: Marketing, Econometrische modellen, Verwachtingen } \\
\hline Free keywords & \multicolumn{3}{|c|}{ Marketing, lucas critique, econometrics } \\
\hline
\end{tabular}




\title{
Marketing Models and the Lucas Critique
}

\author{
Harald J. van Heerde, Marnik G. Dekimpe and William P. Putsis, Jr. ${ }^{1}$
}

August 9, 2004

\begin{abstract}
${ }^{1}$ Harald J. van Heerde is Professor of Marketing at Tilburg University, P.O. Box 90513, 5000 LE Tilburg, The Netherlands; heerde@uvt.nl ; +31 13466 3424. Marnik G. Dekimpe is Professor of Marketing, Catholic University of Leuven \& Professor of Marketing Management, Erasmus University Rotterdam. Naamsestraat 69, 3000 Leuven, Belgium; marnik.dekimpe@econ.kuleuven.ac.be; +32 16326 957. William P. Putsis, Jr. is Professor of Marketing at the Kenan-Flagler Business School, University of North Carolina at Chapel Hill, CB 3490, Chapel Hill, NC 275993490, William_Putsis@unc.edu; +1-919-843-6459.
\end{abstract}

This research was funded by the Netherlands Organization for Scientific Research (Van Heerde) and the Flemish Science Foundation (Dekimpe). The paper was written while the second author was visiting the marketing department at UCLA, and benefited greatly from comments by Barry Bayus, Dominique Hanssens, Koen Pauwels and Baohong Sun. 


\section{Introduction}

The discussion paper by Philip Hans Franses (2004) points out that the Lucas critique has hardly diffused in the marketing literature. In contrast, there has been a heated debate in the economics literature (e.g., Sargent 1979 vs. Sims 1986) about a key thesis of Lucas (1976, p. 41), “given that the structure of an econometric model consists of optimal decision rules of economic agents, and that optimal decision rules vary systematically with changes in the structure of series relevant to the decision maker, it follows that any change in policy will systematically alter the structure of econometric models". 2 Underlying this thesis is the idea that economic agents are forward rather than backward looking, and adapt their expectations and behavior to the new policy (Lindé 2001, p. 986). A key characteristic of policy analysis is the recognition that, because of the policy intervention, the future may be unlike the past (Darnell and Evans 1990). In contrast, econometric (reduced-form) models are backward-looking summaries of past correlational patterns that are assumed to persist in the future, regardless of policy changes (Lindé 2001). Since many marketing models are intended to recommend better marketing policies (Leeflang et al. 2000), the Lucas critique seems to pose a serious threat to the validity of the recommendations. Therefore, it is important to view the implications drawn from previous research in marketing with this critique in mind. The Lucas critique is particularly relevant if three conditions are satisfied: (i) it is indeed applicable in the marketing setting at hand; (ii) the consequences of ignoring it are severe, and (iii) there are no easy solutions available.

A key objective of this article is to investigate to what extent the above three conditions are valid in marketing research. We agree with Franses that there are certainly cases in marketing

\footnotetext{
${ }^{2}$ We primarily focus on households as economic agents. Bronnenberg et al. (in this issue) also consider other agents such as manufacturers and retailers.
} 
in which the Lucas critique is relevant, but that one needs to recognize that the critique may (i) be more relevant for certain types of models, and (ii) potentially more onerous in certain settings. Therefore, while it may be another important item to be considered by reviewers at the top journals in marketing, we feel that there is a potential risk that reviewers use the Lucas critique as another crutch to justify recommending that a manuscript be rejected, much like recent "hot" (and perhaps misused, see e.g., Shugan 2004) topics such as endogeneity, unobserved heterogeneity, and aggregation bias have been used. ${ }^{3}$ To avoid this situation, we identify in the next section conditions under which the critique is applicable. After that, we give some perspectives on the severity of ignoring the Lucas critique. The subsequent section presents various ways to diagnose and accommodate the Lucas critique. We end with a discussion and suggestions for future research. It is our hope that by providing such a "guide", careful reviewers will limit invoking the Lucas critique to those settings where its presence has a severe impact on the managerial relevance and validity of the research.

\section{Relevance of the Lucas Critique for Marketing Models}

We believe there are three key requirements for the Lucas critique to be relevant: (i) economic agents should be aware of the policy change; (ii) economic agents should be motivated to change behavior as a direct consequence of the policy change, and (iii) economic agents should be able to change behavior (cf. Chen, Smith, and Grimm 1992; Steenkamp et al. 2004). This already suggests that behavioral changes may occur with some delay, and that the Lucas critique may be more applicable for models focusing on long-run rather than short-run decisions.

An important consideration is that the Lucas critique (1976) initially concerned macroeconomic models. A key observation is that even for the substantial policy changes typically

\footnotetext{
${ }^{3}$ For an excellent discussion of the care reviewers should use in bringing in only relevant and result-altering criticism in reviews, see John Lynch’s ACR presidential address (Lynch 1998).
} 
studied in macroeconomics, virtually no evidence is found supporting the empirical relevance of the Lucas critique (Ericsson, Hendry and Mizon 1998), even though there still is considerable consensus on its theoretical relevance (Lindé 2001). One could argue that the monetary motivation to adjust behavior due to macro-economic policy changes (e.g., tax rate changes, minimum wage changes) may be much larger than to marketing policy changes, especially in the context of low-budget FPCGs. Indeed, if supermarket shoppers are found to have little knowledge of the price they have just paid (Dickson and Sawyer 1990), how can they be expected to notice price changes, to alter their prices expectations, and to adjust their behavior accordingly? Still, individual consumers may, in some settings, be motivated and able to adjust their behavior once they anticipate changes in marketing-mix values. Note, for example, that Sun, Neslin, and Srinivasan (2003) and Erdem, Imai, and Keane (2003) find evidence for consumers optimally planning their purchases in the ketchup category, even though ketchup obviously represents a very low share of most family budgets. Further, the very nature of consumer search (e.g., Stigler 1961) and the expectations inherent in inter-temporal consumer choice (Putsis and Srinivasan 1994) suggest that consumers may indeed act consistently with the Lucas critique. Although the monetary motivation may be limited, consumers seem to be able to anticipate, e.g., promotions because of their high frequency and regularity. Moreover, due to the storability of items in categories such as ketchup, consumers are able to (re-)distribute their purchases (i.e., their behavior) optimally across time (see also Assunção and Meyer 1993).

One more example in marketing practice in which the three requirements are satisfied is Proctor \& Gamble's policy change in the 90's. Starting in 1991-92, P\&G instituted major reductions in promotion and increases in advertising in an effort to reduce operating costs and strengthen brand loyalty (Ailawadi, Lehmann, and Neslin 2001). The changes were implemented 
across multiple categories and widely publicized, so consumers may well have been aware of the policy change. Since the policy change was permanent and it involved a major reduction in the use of deals and coupons, consumers were motivated to change behavior. ${ }^{4}$ Similarly, in late 1992, Marlboro significantly dropped its price in an attempt to stop its market-share erosion caused by value brands. Consumers were aggressively made aware of the price drop, and were able and motivated to adjust their behavior, as total category sales grew with 2 percent while Marlboro's market share increased by 9 percent (Hoch 1996). As a final example, the largescale price war among Dutch supermarkets that started in October 2003 also satisfies the three conditions. Albert Heijn, the leading supermarket chain, initiated a major (up to 30\%) price reduction on many $(>1,000)$ of its key items (www.dft.nl). Within one day, almost all major competitors followed. In the next days and weeks, all players ran major advertising campaigns announcing that the price reductions would be permanent, as well as a further extension of the price reduction to ever more items. In the above examples, the Lucas critique is likely to apply with full force, in which case policy recommendations based on pre-change data could become problematic.

There are also marketing examples, however, in which at least one of the three requirements is not satisfied, and hence the Lucas critique is less applicable. For example, the pricing structure in the cellular phone industry is not transparent to most consumers, with strongly varying and complex fixed and variable prices for calls and handsets (Danaher, Hardie, and Putsis 2001; Miravete 2002). Therefore, price policy changes may go unnoticed by consumers, and the awareness requirement is not fulfilled. Second, in the retail gasoline (petrol)

\footnotetext{
${ }^{4}$ Strictly speaking, actual "permanency" of the policy change is not a necessary condition for economic agents to adjust their behavior. It suffices that the time horizon of the policy change is perceived to be long enough to warrant such a behavioral adjustment (i.e., causes enough motivation to change). This is one reason why there may be a difference in the long versus short run implications/applicability of the Lucas critique.
} 
industry in many European countries, prices of competing brands tend to move up and down simultaneously (see e.g. www.nmanet.nl), based on the raw crude prices at any particular point in time. These price changes tend to be reported in the press, making consumers aware of them. However, since these price movements typically do not change price differences between suppliers, consumers have no motivation to change their choice behavior in the short run. Further, high switching costs may prevent consumers to react to a policy change even though they may be aware and motivated to do so (no ability). Over time, however, higher prices may encourage individuals to other modes of transport (e.g., hybrid electric vehicles, publictransportation options), suggesting that consumers may indeed react in the long run. Hence, one needs to be careful in levying the Lucas critique in cases such as these, where it may indeed be less relevant. Further, often the relevance of the critique may depend upon whether the time horizon for policy analysis is long or short.

\section{Consequences of Ignoring the Lucas Critique}

A major implication of the previous section is that classical reduced-form models (such as the multinomial choice models for panel data or the log-log model for store-level scanner data) are only valid to analyze the effects of policy changes that consumers are either (i) not aware of, or (ii) not motivated to act on, or (iii) not able to act on, and one may wonder whether such changes would constitute the managerially (most) interesting cases. If the Lucas critique is relevant, and it is ignored, marketing models may yield biased predictions of the effects of marketing policy changes (we refer to the article from Franses for both a concrete illustration and additional references on this issue). Biased parameter estimates are perhaps one of the most serious issues in econometric modeling. Therefore, ignoring the Lucas critique could be considered as fatal a flaw as ignoring endogeneity. Endogeneity happens to be the primary factor affecting price 
elasticity estimates according to a recent meta-analysis (Bijmolt, Van Heerde, and Pieters 2005). To illustrate, their meta model predicts an average price elasticity of -2.5 if endogeneity is ignored, and -3.7 if it is accommodated.

While the Lucas critique may therefore be an issue in some marketing settings, it definitely will not be the only one applied marketing researchers should be concerned about, as correctly pointed out by Franses. We would like to add two further remarks in this respect. First, omitted variable bias may be particularly relevant in many marketing settings, and could play as big a role as the Lucas critique or the endogeneity issue - including or excluding covariates such as a promotion dummy or advertising may affect price elasticity estimates almost as much as ignoring versus accommodating endogeneity (Bijmolt, Van Heerde, and Pieters 2005). Second, a flaw such as ignoring autocorrelation may seem one degree less fatal than flaws leading to biases, since it "only" leads to inefficient parameter estimates. However, we argue that autocorrelation may be a signal of serious model misspecification. If the autocorrelation is caused by omitting predictors uncorrelated with the included predictors, the inefficiency of OLS can be successfully remedied by GLS. For example, suppose that a model for beer sales excludes temperature (which in itself is highly autoregressive) and none of the included (marketing-mix) predictors happens to be correlated with temperature. On the other hand, suppose a model omits relevant variables (e.g., lagged marketing-mix variables) that are correlated with the included predictors (e.g., current marketing-mix variables). In both cases, a residual test will reveal autocorrelation, a seemingly small issue since it "only" leads to inefficient estimates, which is true in the former case. However, in the latter case the parameter estimates for the included predictors are also biased, which cannot be remedied by GLS. Instead, the model specification should be extended with the omitted predictors. 
In summary, it is our view that the Lucas critique should be considered in light of the various other model specification issues at hand. We acknowledge that the consequences of the Lucas critique are potentially severe, but agree with Franses that this should not lead to less attention to more traditional model specification tests.

\section{Ways to Deal with the Lucas Critique}

We briefly discuss three streams in the marketing literature that have either dealt with the Lucas critique or that would benefit from a more explicit consideration of its potential relevance and consequences. Each of these streams is associated with a different paradigm in econometrics, and has become quite popular in academic marketing research.

First, we consider various reduced-form specifications, and a number of procedures (such as varying-parameter models) that might be used to accommodate their sensitivity to the Lucas critique. Next, we consider the VAR \& cointegration literature, where various tests to diagnose the Lucas critique have emerged. The third stream is the structural-equations literature, most notably empirical IO (NEIO) models, which tries to model (and thereby eliminate) the underlying causes for the Lucas critique. We discuss these streams in turn.

\section{Reduced-Form Models}

One of the premises underlying the Lucas critique is that agents anticipate future policies (see also the example in Franses’ article). The marketing literature provides several models with adhoc predictor variables that approximate forward-looking decision making. For example, Sun, Neslin, and Srinivasan (2003) test a multinomial logit model with a dummy predictor variable representing whether a consumer may expect a future promotion, and they find a significant negative effect on current choice probabilities. Van Heerde, Leeflang, and Wittink (2000) use 
lead price promotion variables in a log-log model and they find significant pre-promotion dips. In principle, the parameter estimates for these proxies represent the degree of forward "lookingness" that is present under a specific marketing policy. Therefore, reduced-form models with proxies of this nature may lead to predictions that are very similar to those from structural models, provided the hold-out sample mirrors historically-observed marketing policies (Sun, Neslin and Srinivasan 2003). However, in the event where a researcher wants to consider policy changes that are dramatically different from historically-implemented marketing fluctuations, even "extended" reduced-form models are likely to lead to severe biases. In the event of largemagnitude policy changes (e.g., a 50\% increase in promotional frequency), economic agents would probably adapt their strategies, leading to changes in parameters, which are typically not accommodated in these models. Therefore, just adding a "model component" for forward looking behavior is not necessarily sufficient to fully accommodate the Lucas critique.

The key outcome of the Lucas critique is that response parameters change as a function of policy changes. Partially in response to the Lucas critique, there has been an increased interest in the development and refinement of Time-Varying Parameter Models (Caporale 1998). In marketing, scholars have modeled marketing-mix responsiveness as a function of recent promotion and advertising policies (Foekens, Leeflang, and Wittink 1999 and Mela, Gupta, and Lehmann 1997). One benefit of time-varying parameters over the structural approach is that they do not require the restrictive assumption of a specific game being played among policy makers and economic agents (Amman and Kendrick 2003). Instead, one directly addresses the core of the Lucas critique by explicitly accounting for varying parameters.

On the other hand, if one uses varying-parameter models to predict the effects of a policy change, a key assumption is that the estimated relationship between policy and response 
parameters remains unchanged. Figure 1 illustrates this assumption. In the sample available for estimation, the researcher observed promotional frequencies varying around 20\% (X-axis). The response to promotions (sales multiplier on Y-axis) has been measured by a varying-parameter model, which links the response parameter linearly to the promotional frequency. If the researcher wants to make a prediction for a major policy change such as increasing the promotional frequency to above $50 \%$, the model predicts that the linear relationship still holds. The extent to which this is valid is unclear, yet impossible to quantify in the absence of such extreme observations in the estimation sample.

Figure 1: Hypothetical relationship between policy (X-axis) and response parameter (Y-axis)

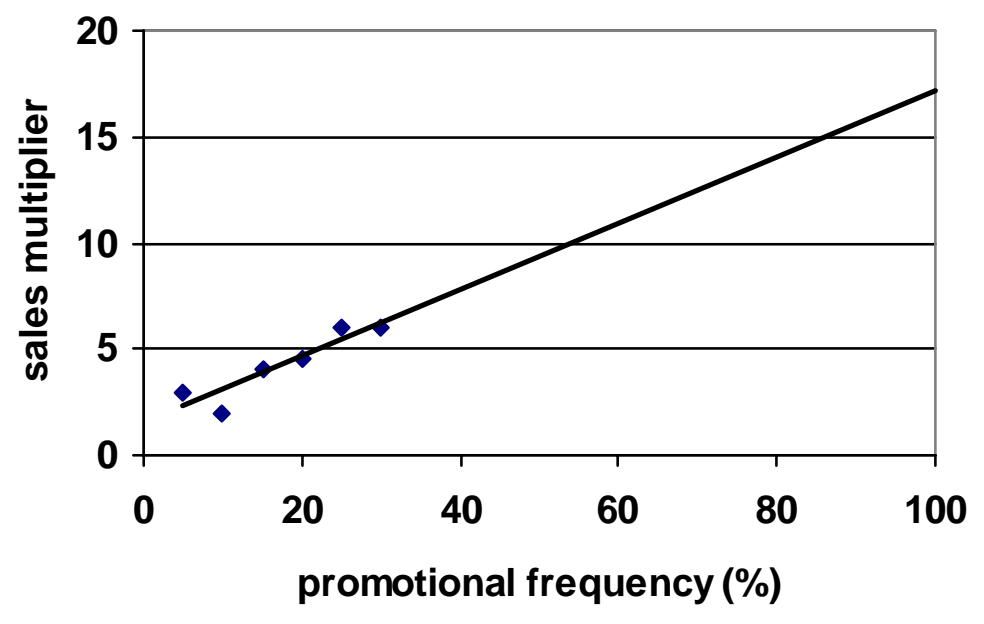

In a way, the varying-parameter approach shifts the problem of assuming constant parameters to the assumption of assuming a constant relationship between policy and parameters. As long as this assumption is acknowledged and, ideally, validated, varying-parameter procedures present a possible approach to deal with the Lucas critique. One possible criticism, 
though, is that the framework is ad hoc, without an underlying economic theory. The structural approach, discussed later, overcomes this shortcoming.

One might consider an intermediate approach that recognizes that the path of parameter variation is likely to consist of persistent - or permanent - components and components that vary stochastically from period to period (see, e.g., Putsis 1998). However, in our view, the persistent portion of the parameter vector is then likely to be subject to the same criticisms as standard reduced-form models, and should be approached cautiously. Indeed, predicting the permanent component of such a model into a hold-out sample in the face of a policy change remains extremely difficult if the policy change has not been accounted for in the sample period.

\section{VAR \& Cointegration Models}

Recently, Vector AutoRegression (VAR) and Vector Error Correction (VECM) models have become popular (see e.g., Nijs et al. 2001; Pauwels, Hanssens and Siddarth 2002) to capture the dynamic interrelationships between various performance measures (e.g., primary demand, sales, market share) and marketing-decision variables (e.g., advertising, price), which are all modeled endogenously. Although VAR (VECM) models are also reduced-form specifications, ${ }^{5}$ we discuss them separately, as some specific approaches to deal with policy analysis and the Lucas critique have been developed in this research tradition.

First, impulse-response functions (IRFs) have been used to simulate the over-time impact of a temporary change in one or more marketing decision variables. These studies are typically very explicit in stating their assumption that the considered marketing-mix change (which they label a "shock") is both unexpected and does not alter the nature of the underlying datagenerating process (see e.g. Dekimpe, Hanssens and Silva-Risso 1999, p. 271; Srinivasan et al.

\footnotetext{
${ }^{5}$ See Darnell and Evans (1990) for a more in-depth discussion on this issue.
} 
2004, p. 627). Put differently, the assumption is that the considered marketing action is small enough to ensure that the Lucas critique does not apply. For example, Srinivasan et al. (2004) explicitly state that they study the over-time profit implications of a single (marginal) price promotion in a high-promotional-intensity context, and not the impact of a major policy change. While this clearly reduces the IRFs' sensitivity to the Lucas critique, it also restricts their use to more tactical "day-to-day” marketing operations (i.e., an additional promotion), while more strategic (and also more dramatic) regime changes, such as a doubling in promotional intensity, tend to fall outside their scope.

Given the flexibility of VAR/VECM models to capture a wide variety of dynamic effects and channels of influence, it is quite tempting to also use them to study more drastic policy changes. Pauwels (2004), for example, uses restricted policy simulations in which some endogenous variables are assumed to remain in their steady state after a change in one or more marketing-decision variables, while others are allowed to change. Within that framework, various forecasting experiments are conducted. Pauwels compares scenarios where only demand changes with instances where also competitors respond and/or the firm expands its marketing actions. He thereby assumes that the imposed restrictions do not change the data-generating process. However, given the radical nature of the considered changes, this may be a heroic assumption. Restricted policy simulations are also implemented in Horváth (2003), where various parameters (e.g., all parameters reflecting competitive reactions) are restricted to zero to disentangle the relative impact of various channels of influence reflected in an initially more extended VAR model. Again, these drastic scenario simulations make the results much more sensitive to the Lucas critique than traditional IRF derivations. 
Other researchers have focused not so much on the multitude of VAR model parameters (and the IRFs derived from them), but rather on the presence/absence of a long-run equilibrium (cointegrating) relationship between stochastically-trending performance and marketing-control variables (see e.g. Franses, Kloek, and Lucas 1999). The fact that a relationship reflects a longrun equilibrium does not vaccinate it to the Lucas critique, however, as policy changes (interventions) may well alter the long-run properties of the system. Fortunately, whether or not a given cointegration vector is invariant to certain policy changes can be assessed empirically through super-exogeneity tests (see Ericsson 1992 for a review). ${ }^{6}$ As pointed out by Franses, parameter-stability tests are central in super-exogeneity tests (see e.g. Ahamuda 1992; Lindé 2001). While applied relatively rarely in the marketing time-series literature (see Naik and Raman 2003 for a notable exception), super-exogeneity tests have become fairly standard diagnostic tools in the economics literature. This neglect in marketing is unfortunate, as the empirical presence of super exogeneity renders one’s policy implications immune to the Lucas critique. However, super exogeneity is always established with respect to a specified class of interventions (e.g., those that occurred within the estimation sample), and not necessarily for interventions outside that class (Ericsson 1992). Hence, while super-exogeneity tests allow to check empirically whether the Lucas critique holds for some marketing-policy changes, they do not offer a stamp of approval for all (e.g., those historically not yet observed). Nor do these diagnostics offer further guidelines to the applied marketing researcher on how to proceed when the null hypothesis of super exogeneity is rejected. In that case, one could either argue there is no value at all in what-if type simulations (Sargent 1979), or adjust one's degree of confidence in the policy implications (Sims 1986). More research on this issue is called for. One option may be to stimulate managers to then engage in controlled field experiments (see e.g. Eastlack and

\footnotetext{
${ }^{6}$ Note, though, that the notion of super exogeneity is not restricted to instances where cointegration is present.
} 
Rao 1986, or the split-cable experiments described in Lodish et al. 1995), an option definitely more feasible in marketing than in macro-economics.

We concur with Franses that super-exogeneity tests should become an integral part of the standard diagnostic tool box, as they either offer empirical justification for the policy analysis at hand (in case super exogeneity is established for a certain type of policy change), ${ }^{7}$ or, at the very least, offer a clear warning signal against putting too much faith in potentially flawed policy simulations (in case super exogeneity could not be established). Similarly, many decision support models currently used in industry are built around reduced-form models. Their ease of use lends themselves very well to all kinds of what-if simulations. In the absence of any diagnostics on potential violations of the super-exogeneity assumption, managers may put unjustified faith on the outcomes of their decision-support system, especially for simulations beyond the scope of historically-observed marketing decision variables.

\section{Structural Models}

For major policy changes, the structural-equation approach (see, e.g., Sun, Neslin, and Srinivasan 2003 and Erdem, Imai, and Keane 2003) is often well-suited, since this approach can explicitly account for changes in the optimal decision rules of economic agents. In the structural-equation approach, the modeler assumes that agents optimize an objective function, based on current and expected marketing-mix values. A key advantage of the structural approach is that it is possible to incorporate virtually any form of behavior on the part of agents, with the agents' optimal response to any marketing policy (change) being incorporated within the agents' optimization. This can lead to deeper insights without major concern for the Lucas critique,

\footnotetext{
${ }^{7}$ Assuming, of course, that currently-available super-exogeneity tests have sufficient power to detect parameter instability in the response relationship at hand. This was recently questioned in a simulation study by Lindé (2001).
} 
provided that the agents' optimization is specified correctly, that the various assumptions about the game being played between agents is correct, and provided that the form of interaction between agents reflects reality. Further, the basic assumptions of underlying utility theory need to be met (which may be partially called into question by some of the research on behavioral decision theory and mental accounting), and the underlying functional-form assumptions must be acceptable econometrically. If these assumptions are violated in reality (see Cotterill and Putsis 2001 for an example of testing such assumptions), the structural approach can give a false sense of security. For example, Kadiyali, Sudhir, and Rao's (2001) statement that the structural empirical IO (NEIO) models they reviewed were "not subject to the well-known problems of the Lucas critique” (p. 163) might lead a reader to naively estimate and/or use such models without regard to the Lucas critique. We would argue that if all the criteria described above are met, then this is a fair assertion. However, for improperly specified objective functions, for cases where the incorrect game is being studied, and in cases of functional-form misspecification, the consequences of the Lucas critique remain unknown, both empirically as well as theoretically. We encourage future researchers to investigate this issue in greater depth.

Finally, perhaps as importantly, structural models, such as the NEIO approach, can be used to set out simulations and/or decision-support systems based on the empirical results. Still, the general principle holds that policy simulations are only valid provided the model they are based on is correctly specified. However, the implied assumption of a single true datagenerating process represents a striking inconsistency with the common practice of evaluating policy implications of two or more competing policy models (Granger and Deutsch 2001). It is fair to say that most currently available NEIO models in marketing do not yet incorporate all (often dynamic) features that have been well documented in other modeling approaches (e.g. 
stockpiling, long-run marketing effects), making it unlikely that they indeed capture all relevant phenomena. Currently, the impact of the static nature of most structural models in a truly dynamic environment on the applicability of the Lucas critique remains largely unknown. If, for example, long-term effects are ignored, a structural model may suffer from myopic (short-term) optimization, which will hamper the validity of its policy implications. Another potential disadvantage is that diagnostic checks for parameter stability are underdeveloped (or underutilized) relative to, for example, VAR models.

\section{Discussion and Future Research}

The Lucas critique not only poses significant threats to the validity and practical implications of marketing models, but also offers a wide range of research opportunities. We have discussed that various modeling paradigms (Reduced-form models, VAR/Cointegration models and Structural models) have different issues associated with the Lucas critique. We do not propose that only one of them is right, and we agree with Litterman (1984, p. 38) that "To generate policy conclusions, all models require similar identifying assumptions, which are likely difficult to defend, and all are thus subject to a large degree of uncertainty". We hope that researchers from the various paradigms are able to appreciate the benefits of the alternative approaches, while not being overwhelmed by their disadvantages.

Research that tries to overcome these disadvantages is highly desirable. For example, one could consider imposing a (minimal) set of restrictions on the contemporaneous effects in a VAR model. The resulting structural VAR models (SVAR) would maintain their usual dynamic flexibility, while giving the residuals (and subsequent shocks in the derivation of the IRFs) a more structural interpretation (see Pauwels 2004 for a marketing application). A subsequent step may be to account for the effects of forward-looking behavior on the part of consumers (or other 
economic agents) on the validity of these restrictions, and hence, on the consistency of the model's parameter estimates, as discussed in Keating (1990). Next, Bayesian estimation may explicitly allow for the user's confidence in the parameter estimates (see e.g., Litterman 1984 for a discussion on the usefulness of Bayesian VAR Models in policy analysis, or Fok et al. 2004 for a marketing application of Hierarchical Bayes error-correction modeling). Furthermore, timevarying parameters models in marketing (so far) have not explicitly been developed to accommodate the Lucas critique. One possibility is to adapt the latest Dynamic Linear Models that allow for Bayesian parameter updates for each new time period (Neelamegham and Chintagunta 2004, Van Heerde, Mela, and Manchanda 2004). We may use management judgment to specify the prior-effect expectations of a policy change, and combine that with the pre-change data to come up with the posterior. Conversely, while structural models may be less "susceptible" to the Lucas critique, they may suffer from other, potentially as onerous, econometric concerns (e.g., endogeneity, no dynamic effects, omitted-variable biases, etc.). Finally, we note that structural models would benefit from more rigorous diagnostic checks to validate whether parameters are indeed constant.

One major implication that results from the Lucas critique is that the use of hold-out samples and simulations in practice should be conducted with closer scrutiny and a higher degree of skepticism. A major limitation of most current hold-out samples used in marketing studies is that they are not systematically different from the estimation sample. To seriously validate various approaches to accommodate the Lucas critique, it is critical to subject them to a true test: predictive validity for data in which there is a major change in policy that satisfies the three conditions we proposed (awareness, motivation and ability). An extreme example would be a store increasing its promotional frequency by $50 \%$ within the sample period. In such a case, the 
model could be calibrated on the low-frequency period, and its predictive accuracy should also be assessed for the high-frequency hold-out period.

There also seem to be many research opportunities into additional substantive marketing areas in which agents can be assumed to be forward looking. Consumers and retailers may anticipate product changes in categories with constantly improving technology, such as digital cameras (Song and Chintagunta 2003). Similarly, they may anticipate last-minute travel deals, fashion sales at the end of the season, and new-car introductions. Agents may also have expectations about the diffusion rates for new technologies, which require a substantial user base (such as wireless laptops, or wide-screen televisions). For each setting, the opportunity and motivation to be forward looking may differ. Therefore, we may expect idiosyncratic expectation-formation patterns and unique effects on current (purchase) behavior. Modeling anticipations across a wide scope of settings can lead to more insights into variations in the nature, degree and effects of forward-looking behavior.

We hope that this paper and the papers by Franses and Bronnenberg et al. in the current issue increase among marketing modelers (i) the awareness for the Lucas critique; (ii) the motivation to appropriately test for it, and (iii) the ability to accommodate the outcomes or causes in their models. We feel it will be an empirical issue to what extent marketing-policy changes will actually give rise to the Lucas critique. The lack of statistical support for the Lucas critique in a highly aggregate macro-economic context (Ericsson, Hendry and Mizon 1998) should, however, not serve as an excuse for its continued neglect in, often more disaggregate, marketing settings. 


\section{References}

Ahumada, Hildegart (1992), “A Dynamic Model of the Demand for Currency: Argentina 19771988,” Journal of Policy Modeling, 14 (6), 335-361.

Ailawadi, Kusum L., Donald R. Lehmann, and Scott A. Neslin (2001), "Market Response to a Major Policy Change in the Marketing Mix: Learning from Proctor \& Gamble's Value Pricing," Journal of Marketing, 65 (January), 44-61.

Amman, Hans M and David A Kendrick (2003), "Mitigation of the Lucas Critique with Stochastic Control Methods," Journal of Economic Dynamics \& Control, 27 (11-12), 2035-2057.

Assunção, Joãao and Robert J. Meyer (1993), “The Rational Effect of Price Promotions on Sales and Consumption,” Management Science, 39 (5), 517-535.

Bijmolt, Tammo H.A., Harald J. Van Heerde, and Rik Pieters (2005), "New Empirical Generalizations on the Determinants of Price Elasticity" Journal of Marketing Research, 42 (February or May), forthcoming.

Caporale, Tony (1998), "The Impact of Monetary Regime Changes: Some Exchange Rate Evidence," Journal of Economic Behavior \& Organization, 35 (1), 85-94.

Chen, Ming-Jer, Ken. G. Smith, and Curtis M. Grimm (1992), "Action Characteristics as Predictors of Competitor Response,” Management Science 38 (March), 439-455.

Cotterill, Ronald and William P. Putsis, Jr. (2001), "Do Models of Vertical Strategic Interaction for National and Store Brands Meet the Market Test?,” Journal of Retailing, 77 (1), 83-109.

Danaher, Peter, Bruce Hardie, and William P. Putsis, Jr. (2001), "Marketing Mix Variables and the Diffusion of Successive Generations of a Technological Innovation," Journal of Marketing Research, 38 (4), 501-514.

Darnell, Adrian C. and J. Lynne Evans (1990), The Limits of Econometrics, Edward Elgar Publishing Limited.

Dekimpe, Marnik G., Dominique M. Hanssens and Jorge M. Silva-Risso (1999), "Long-run Effects of Price Promotions in Scanner Markets," Journal of Econometrics, 89, 269-291.

Dickson, Peter R. and Alan G. Sawyer (1990), "The Price Knowledge and Search of Supermarket Shoppers,” Journal of Marketing, 54 (July), 42-53.

Eastlack, Joseph O. Jr. and Ambar G. Rao (1986), "Modeling Response to Advertising and Pricing Changes for "V-8” Cocktail Vegetable Juice,” Marketing Science, 5 (3), 245-259.

Erdem, Tulin, Susumu Imai, and Michael P Keane (2003), "Brand and Quantity Choice Dynamic Under Price Uncertainty," Quantitative Marketing and Economics, 1 (1), 5-64.

Ericsson, Neil E. (1992), "Cointegration, Exogeneity, and Policy Analysis: An Overview”, Journal of Policy Modeling, 14 (June), 251-280.

Ericsson, Neil E., David F. Hendry and Grayham E. Mizon (1998), "Exogeneity, Cointegration, and Economic Policy Analysis,” Journal of Business and Economic Statistics, 16, 370387.

Foekens, Eijte W., Peter S.H. Leeflang, and Dick R. Wittink (1999), "Varying Parameter Models to Accommodate Dynamic Promotion Effects," Journal of Econometrics, 89, 249-268.

Fok, Dennis, Csilla Horváth, Richard Paap and Philip Hans Franses (2004), “ A Hierarchical Bayes Error Correction Model to Explain Dynamic Effects of Promotions on Sales,” unpublished manuscript, Erasmus University Rotterdam. 
Franses, Philip Hans (2003), “On the Use of Marketing Models for Policy Simulation,” Unpublished Manuscript, Erasmus University Rotterdam.

Franses, Philip Hans, Teun Kloek and A. Lucas (1999), “Outlier Robust Analysis of Long-run Marketing Effects for Weekly Scanning Data,” Journal of Econometrics, 89, 293-315.

Granger, Clive W.J. and Melinda Deutsch (2001), "Comments on the Evaluation of Policy Models,” in Essays in Econometrics: Spectral Analysis, Seasonality, Nonlinearity, Methodology, and Forecasting, Ghysels, E., N.R. Swanson and M.W.Watson (Eds), Cambridge University Press, NY, pp. 317-335.

Hoch, Stephen J. (1996), “How Should National Brands Think about Private Labels?” Sloan Management Review, Winter, 89-102.

Horváth, Csilla (2003), "Dynamic Analysis of Marketing Systems”, Doctoral Thesis University of Groningen, Alblasserdam: Labyrint Publication.

Kadiyali, Vrinda, K. Sudhir and Vithala R. Rao (2001), "Structural Analysis of Competitive Behavior: New Empirical Industrial Organization Methods in Marketing,” International Journal of Research in Marketing, 18 (1-2), 161-186.

Keating, John W. (1990), “Identifying VAR Models Under Rational Expectations,” Journal of Monetary Economics, 25. 453-476.

Leeflang, Peter S.H., Dick R. Wittink, Michel Wedel and Philippe A. Naert (2000), Building Models for Marketing Decisions, Kluwer Academic Publishers.

Lindé, Jesper (2001), “Testing for the Lucas Critique: A Quantitative Investigation," The American Economic Review," 91 (4), 986-1005.

Litterman, Robert B. (1984), "Forecasting and Policy Analysis With Bayesian Vecror Autoregression Models," Federal Reserve Bank of Minneapolis Quarterly Review (Fall), 30-41.

Lodish, Leonard M., Magid Abraham, Stuart Kalmenson, Jeanne Livelsberger, Beth Lubetkin, Bruce Richardson and Mary Ellen Stevens (1995), "How T.V. Advertising Works: A Meta-Analysis of 389 Real World Split Cable T.V. Advertising Experiments,” Journal of Marketing Research, 32 (May), 125-139.

Lucas, Robert E. (1976), “Econometric Policy Evaluation: A Critique,” Carnegie-Rochester Conference Series on Public Policy, 1, 19-46.

Lynch, John G. (1998), "Presidential Address: Reviewing,” J.W. Alba, J.W. Hutchinson, eds., Advances in Consumer Research, vol. XXV, Association for Consumer Research, Provo, UT, 1-6.

Mela, Carl F., Sunil Gupta, and Donald R. Lehmann (1997), "The Long-Term Impact of Promotion and Advertising on Consumer Brand Choice," Journal of Marketing Research, 34 (May), 248-261.

Miravete, Eugenio (2002), “Choosing the Wrong Calling Plan,” American Economic Review, pp. 297-310.

Naik, Prasad A. and Kalyan Raman (2003), "Understanding the Impact of Synergy in Multimedia Communications,” Journal of Marketing Research, 40 (November), 375-388.

Neelamegham, Ramya and Pradeep K. Chintagunta (2004), "Modeling and Forecasting the Sales of Technology Products," Quantitative Marketing and Economics, forthcoming.

Nijs, Vincent, Marnik G. Dekimpe, Jan-Benedict E.M. Steenkamp and Dominique M. Hanssens (2001), “The Category Demand Effects of Price Promotions,” Marketing Science, 20 (1), 1-22. 
Pauwels, Koen (2004), "How Dynamic Consumer Response, Dynamic Competitor Response and Expanded Company Action Shape Long-term Marketing Effectiveness,” Marketing Science, forthcoming.

Pauwels, Koen, Dominique M. Hanssens and S. Siddarth (2002), “The Long-term Effects of Price Promotions on Category Incidence, Brand Choice and Purchase Quantity,” Journal of Marketing Research, 39 (November), 421-439.

Putsis, Jr., William P. (1998), "Parameter Variation and New Product Diffusion,” Journal of Forecasting, 17(3/4), 231-258.

Putsis, Jr., William P., and Narasimhan Srinivasan (1994), "Buying or Just Browsing? The Duration of Purchase Deliberation,” Journal of Marketing Research, 393-402.

Sargent, Thomas J. (1979), "Estimating Vector Autoregressions Using Methods Not Based on Explicit Economic Theories,” Federal Reserve Bank of Minneapolis Quarterly Review, 3 (Summer), 8-15.

Shugan, Steve (2004), “Editorial: Endogeneity in Marketing Decision Models,” Marketing Science, 23 (1), 1-3.

Sims, Chrisopher A (1986), "Are Forecasting Models Usable for Policy Analysis?," Federal Reserve Bank of Minneapolis Quarterly Review (Winter), 2-16.

Song, Inseong and Pradeep K. Chintagunta (2003), "A Micromodel of New Product Adoption with Heterogeneous and Forward-Looking Consumers: Application to the Digital Camera Category," Quantitative Marketing and Economics, 1 (4), 371-407.

Srinivasan, Shuba, Koen Pauwels, Dominique Hanssens and Marnik G. Dekimpe (2004), “Do Promotions Benefit Manufacturers, Retailers, or Both?” Management Science, 617-629.

Steenkamp, Jan-Benedict E.M., Vincent Nijs, Dominique M. Hanssens and Marnik G. Dekimpe (2004), “Competitive Reactions to Advertising and Promotion Attacks," Marketing Science, forthcoming.

Stigler, George (1961), “The Economics of Information, Journal of Political Economy, 65, 213225.

Sun, Baohong, Scott A. Neslin, and Kannan Srinivasan (2003), "Measuring the Impact of Promotions on Brand Switching When Consumers Are Forward Looking," Journal of Marketing Research, 40 (November), 389-405.

Van Heerde, Harald J., Peter S.H. Leeflang, and Dick R. Wittink (2000), "The Estimation of Preand Postpromotion Dips with Store-Level Scanner Data," Journal of Marketing Research, 37 (August), 383-395.

Van Heerde, Harald J., Carl F. Mela, and Puneet Manchanda (2004), "The Dynamic Effect of Innovation on Market Structure," Journal of Marketing Research, 41 (May), 166-183. 


\section{Publications in the Report Series Research* in Management}

\section{ERIM Research Program: "Marketing"}

\section{4}

Account Managers Creation of Social Capital: Communal and Instrumental Investments and Performance Implications Willem Verbeke, Frank Belschak, Stefan Wuyts and Richard P. Bagozzi

ERS-2004-011-MKT

http://hdl.handle.net/1765/1166

The Adaptive Consequences of Pride in Personal Selling

Willem Verbeke, Frank Belschak and Richard P. Bagozzi

ERS-2004-012-MKT

http://hdl.handle.net/1765/1167

Coping with Sales Call Anxiety and Its Effects on Protective Actions

Frank Belschak, Willem Verbeke and Richard P. Bagozzi

ERS-2004-013-MKT

http://hdl.handle.net/1765/1172

On The Predictive Content Of Production Surveys: A Pan-European Study

Aurélie Lemmens, Christophe Croux and Marnik G. Dekimpe

ERS-2004-017-MKT

http://hdl.handle.net/1765/1175

Advertising effects on awareness, consideration and brand choice using tracking data

Philip Hans Franses and Marco Vriens

ERS-2004-028-MKT

http://hdl.handle.net/1765/1266

How To Seize a Window of Opportunity: The Entry Strategy of Retail Firms into Transition Economies

Katrijn Gielens and Marnik G. Dekimpe

ERS-2004-038-MKT

http://hdl.handle.net/1765/1581

Channel power in multi-channel environments

Sonja Gensler, Marnik G. Dekimpe \& Bernd Skiera

ERS-2004-041-MKT

http://hdl.handle.net/1765/1334

Marketing Models and the Lucas Critique

Marnik G. Dekimpe

ERS-2004-080-MKT

Understanding Brand and Dealer Retention in the New Car Market: The Moderating Role of Brand Type

P.C. Verhoef, F. Langerak and B. Donkers

ERS-2004-084-MKT

http://hdl.handle.net/1765/1613

* A complete overview of the ERIM Report Series Research in Management: https://ep.eur.nl/handle/1765/1

ERIM Research Programs:

LIS Business Processes, Logistics and Information Systems

ORG Organizing for Performance

MKT Marketing

F\&A Finance and Accounting

STR Strategy and Entrepreneurship 